\title{
RANCANG BANGUN SISTEM SMS GATEWAY SEBAGAI FASILITAS PERMOHONAN CUTI KARYAWAN
}

\author{
Maimunah $^{1}$ \\ Supra Singgih ${ }^{2}$ \\ Anwar Supriyadi ${ }^{3}$ \\ Dosen Jurusan Teknik Informatika STMIK Raharja ${ }^{1}$, Mahasiswa Jurusan Teknik Informatika \\ STMIK Raharja ${ }^{2}$, Mahasiswa Teknik Informatika STMIK Raharja ${ }^{3}$ \\ J1 Jenderal Sudirman no.40, Modern, Cikokol Tangerang ${ }^{1,2,3}$ \\ Email : maimunah@raharja.info,suprasinggih@raharja.info,anwar.supriyadi@raharja.info
}

\begin{abstract}
ABSTRAK
Perkembangan teknologi informasi saat ini semakin pesat salah satunya menyangkut sumber daya alam (SDM) karyawan pada lingkup perusahaan misalnya karyawan saat ini, dirasa semakin dibutuhkan oleh setiap instansi. Salah satu fungsi yang dibutuhkan dalam pengolahan sumber daya manusia yaitu mengenai pengolahan cuti karyawan, pada PT Bermuda Comunication yang bergerak dalam bidang Appertising jasa pembuatan sticker, pin, poster, flyer, spanduk, x-banner, roll banner, one way vision, blocknot, setiap perusahaan harus memberikan hak cuti untuk karyawannya. Masalah yang terjadi sebelumnya proses cuti masih menggunakan cara manual, sehingga perlu adanya pengelolaan proses cuti yang terkomputerisasi. Dalam memenuhi hal tersebut maka dibangun sebuah fasilitas sistem permohonan cuti karyawan berbasis aplikasi SMS Gateway. Sistem ini dibangun menggunakan software Gammu dengan menggunakan bahasa pemrograman PHP sebagai awal peng-inputan data pengajuan yang disimpan pada database MySQL, kemudian dihubungkan dengan konsep client-server yang sesuai dalam Osi layer, serta output hasil memanfaatkan fasilitas sms gateway. Dengan adanya sistem aplikasi permohonan cuti karyawan berbasis SMS Gateway ini maka proses layanan cuti pegawai menjadi lebih mudah dan lebih cepat. Proses pengajuan, pengecekan dan pengambilan keputusan hak cuti pegawai dapat dilakukan secara sistematis. Selain itu,proses pengajuan cuti bisa menjadi lebih transparan.
\end{abstract}

Kata kunci : Sumber Daya Manusia (SDM), Aplikasi.Cuti, Karyawan.

\section{ABSTRACT}

The development of information technology is growing rapidly one of which involves natural resources (HR) employees at the company scope for example, employees at this time, felt increasingly required by each agency. One of the functions required in the processing of human resources in the processing of employee leave, the PT bermuda comunication engaged in appertising manufacturing services stickers, pins, posters, flyers, banners, x-banner, roll banner, one way vision, blocknot, every company must give entitlement to karyawanya. Problems that occur before the leave still use manual, so it is necessary to leave the computerized management process. In meeting these conditions, built a facility employee leave request system based SMS Gateway application. The system is built using Gammu software using PHP programming language as early as the lawyersubmitted data input is stored in a MySQL database, then connected with the concept of client-server suite in Osi layers, and output results utilizing sms gateway facilities. With a 
system of employee leave application for SMS-based Gateway is the employee leave the service process becomes easier and faster. The process of filing, checking and decision making employee leave entitlements can be carried out systematically. In addition, the leave application process could be more transparent.

Keywords: Human Resources (HR), applications leave, Employee.

\section{PENDAHULUAN}

Saat ini teknologi sangat berkembang dengan pesatnya, kebutuhan manusia atas informasi, di suatu perusahaan dan aplikasi-aplikasi komputer yang semakin baik di setiap instansi perusahaan, Dengan berkembangnya teknologi dapat membantu tugas-tugas penting pada perusahaan.Cuti merupakan salah satu hak karyawan. Cuti dapat digunakan oleh karyawan untuk tidak masuk kerja dengan alasan tertentu, misalkan refreshing, istirahat sakit, melahirkan, menunaikan kewajiban agama, dan keperluan lain sesuai dengan ketentuan cuti pada masing masing organisasi. Pengambilan cuti karyawan yang berjalan di perusahaan PT Bermuda Communication, masih memiliki beberapa kekurangan, seperti contoh yang sering terjadi , bila ada karyawan yang lupa dengan sisa hak cuti yang dimiliki atau ada karyawan yang memanipulasi data cuti, hal tersebut tidak akan langsung diketahui, hal ini dikarenakan data cuti yang diberikan karyawan harus dicocokkan ulang dengan data yang tersimpan sementara, setelah data dicocokan barulah data akan diinputkan ke komputer induk sesuai dengan isi dari kertas cuti.

Dengan Teknologi sms gateway merupakan solusi yang dapat di manfaatkan untuk membantu pemanfaatan fasilitas SMS sebagai salah satu aplikasi ponsel yang akan dibahas menggunakan komponen Gammu yang menjembatani pentransferan data-data sms dari handphone ke komputer atau sebaliknya. Dalam setiap pekerjaan HRD diharapkan dapat membuat para karyawan tidak lagi harus mendapatkan informasi tersebut dengan datang langsung kepegawaian tetapi hanya cukup mengakses internet dan mengakses website PT Bermuda Communication dengan mudah tidak perlu waktu lama untuk mengetahui informasi cuti Karyawan. Program aplikasi ini diupayakan nantinya sangat membantu dan mempermudah serta mempercepat akses informasi tersebut.

Berdasarkan latar belakang diatas, peneliti akan memaparkan konsep dasar sms menggunakan Gammu sebagai layanan sms gateway untuk informasi cuti karyawan yang ada di PT Bermuda Communication khususnya Permohonan Cuti Karyawan. Agar tujuan penelitian serta permasalahan ini tidak menyimpang, maka pokok permasalahan yang peneliti ambil dibatasi dengan ruang lingkup sebagai berikut, pembuatan SMS Gateway hanya mencangkup pada Sistem Pengajuan Cuti Karyawan dalam hal ini menggunakan bahasa pemrograman PHP, Adobe Dreamwever CS6, Database MySQL, Apache Webserver yaitu Xampp 1.7.2 serta driver Gammu. Serta hanya memberikan layanan SMS permohonan cuti kepada karyawan dengan menggunakan perangkat Wavecom M1306M serta sistem operasi Windows 8 yang digunakan untuk menghubungkannya ke komputer. Untuk itu dalam penyusunan penelitian ini, peneliti mengambil judul Rancang Bangun Sistem Sms Gateway Sebagai Fasilitas Permohonan Cuti Karyawan. Sistem komputerisasi ini diharapkan dapat memberikan kemudahan-kemudahan dalam memperoleh informasi yang dibutuhkan karyawan.

\section{PERMASALAHAN}

Permasalahan pada PT Bermuda Communication adalah masalah yang terjadi sebelumnya proses cuti masih menggunakan cara manual, sehingga perlu adanya pengelolaan proses cuti yang terkomputerisasi selain itu pada perusahaan ini belum 
menggunakan program aplikasi SMS servis dalam hal sistem informasi Cuti karyawan, sehingga pada PT Bermuda Comunication, karyawan masih harus mengajukan permohonan cuti kepada atasan langsung untuk dimintakan persetujuan melalui tanda tangan kemudian disampaikan lagi ke Personalia untuk dimintakan persetujuan lagi melalui tanda tangan. Karena Pengajuan cuti karyawan merupakan suatu hak yang di dapatkan oleh pegawai, sekurang-kurangnya 12 hari cuti tahunan jika cuti pegawai terdiri dari cuti tahunan, cuti besar, cuti sakit, cuti bersalin, cuti karena alasan penting dan cuti di di luar tanggungan Perusahaan.

Permasalahan yang lain kadangkala atasan langsung tidak bisa mengetahui rencana pengambilan cuti pegawai lain, yang dapat berpengaruh pada rencana pengambilan cuti bahkan bisa terjadi bentrok antara cuti pegawai, dikarenakan atasan langsung tidak bisa melakukan monitoring cuti pegawainya, cuti karyawan harus di kelola dengan baik, karena dapat mempengaruhi kinerja pegawai bahkan kinerja organisasi, dengan pengelolaan cuti secara online, akan meningkatkan performa pegawai, pada akhirnya juga meningkatkan kinerja organisasi dalam mencapai tujuan organisasi. Hal inilah yang menghambat para karyawan tidak bisa cuti. Dengan keadaan inilah yang mendorong Peneliti untuk mengadakan penelitian serta membuat system aplikasi untuk mempermudah semua proses Cuti Karyawan di PT Bermuda Communication.

\section{LANDASAN TEORI}

\section{Pengertian Perancangan Sistem}

Perancangan sistem adalah fase pengembangan sistem yang mendefinisikan bagaimana sistem informasi akan melakukan perancangan untuk mendapatkan solusi pemecahan masalah.[1]

Perancangan sistem yaitu tahap untuk melakukan perancangan aplikasi, yang dapat 3 (tiga) tahapan perancangan seperti perancangan interface, perancangan isi, dan perancangan program.

Design system merupakan tahap yang dilakukan setelah melakukan tahap analisis sistem, dan mendapatkan gambaran jelas tentang apa yang harus dilakukan, atau tahap selanjutnya yang harus dilakukan adalah membuat desain sistem.[2]

\section{Pengertian Sms Gateway}

SMS Gateway dapat didefinisikan sebagai suatu sistem atau mekanisme yang memfasilitasi transisi SMS dengan mengubah pesan dari beberapa jenis media komunikasi untuk lalu lintas jaringan seluler " sistem SMS gateway mirip dengan konsep email biasa atau SMS dalam hal sistem menerima pesan dari klien pengirim dan kemudian menyampaikan ke klien penerima.[3]

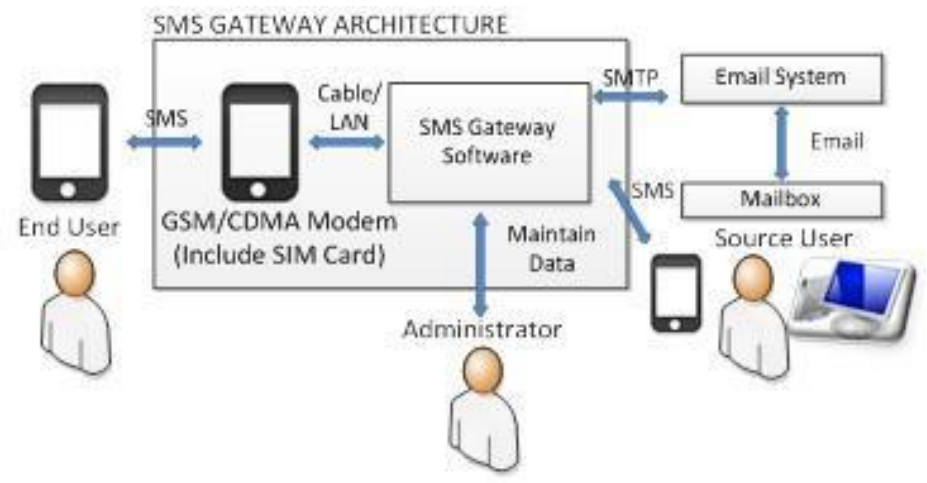

Gambar 1 SMS Gateway 
SMS Gateway memungkinkan untuk sebuah pesan dapat di kirimkan dari sebuah aplikasi melalui jaringan operator telekomunikasi untuk di kirimkan ke nomor nomor tujuan. Dengan menggunakan aplikasi SMS Gateway, sumber data bisa didapatkan langsung dari basis data untuk selanjutnya di olah menjadi informasi dan dikirimkan secara sistemik / tanpa manual kepada banyak nomor dalam satu waktu.[4]

\section{Cara kerja SMS Gateway}

Mekanisme kerja pengiriman SMS dibagi menjadi 3 bagian yaitu:

1. Intra-operator SMS: pengiriman SMS dalam satu operator. SMS yang dikirimkan oleh pengirim akan terlebih dahulu masuk ke SMSC operator nomor pengirim, kemudian SMSC akan mengirimkan ke nomor yang dituju secara langsung. Penerima kemudian akan mengirimkan delivery report yang menyatakan bahwa SMS telah diterima ke SMSC. SMSC kemudian meneruskan report tersebut ke nomor pengirim SMS, disertai status proses pengiriman SMS tersebut.

2. Inter-operator SMS: pengiriman SMS antar operator yang berbeda. Yang membedakan adalah mekanisme ini terdapat dua SMSC yaitu SMSC pengirim dan SMSC penerima. SMS yang dikirim akan masuk ke SMSC pengirim dan diteruskan ke SMSC penerima, setelah itu SMS dikirimkan ke telepon seluler tujuan. Demikian juga dengan delivery report akan diterima terlebih dahulu oleh SMSC penerima, kemudian diteruskan ke SMSC pengirim SMS. Komunikasi antar SMSC dapat berjalan jika telah terdapat kesepakatan kerja sama antaroperator tersebut, jika tidak terdapat kesepatakan akan menyebabkan SMS yang dikirim dengan nomor tujuan dengan operator berbeda tidak akan sampai pada nomor tujuan yang dituju.

3. SMS Internasional: pengirim SMS dari operator suatu negara ke negara lain. SMS internasional pada hakekatnya sama dengan mekanisme inter-operator, yang membedakan hanya pada SMSC nomor penerima adalah SMSC operator luar negeri dan perlu pembambahan kode negara pada nomor tujuan penerima SMS.[5]

\section{Pengertian Permohonan Cuti Karyawan}

Menurut Peraturan Menteri Ketenagakerjaan Republik Indonesia No.13 tahun 2003 pasal 79, Pengusaha adalah wajib memberi waktu istirahat dan cuti kepada perkerja/buruh.[6]

\section{Pengertian Pemrograman PHP}

Coding merupakan tahap implementasi hasil desain ke dalam baris-baris program, Untuk memulai program PHP, kita dapat memulainya dengan mengenal sebuah tag pengenal PHP yang digunakan menuliskan kode PHP.

PHP adalah Bahasa server-side -scripting yang menyatu dengan HTML untuk membuat halaman web yang dinamis. Karena PHP merupakan server-side-scripting maka sintaks dan perintah-perintah PHP akan diesksekusi diserver kemudian hasilnya akan dikirimkan ke browser dengan format HTML.[7]

\section{Definisi MySQL}

\section{Pengertian MySQL}

MySQL adalah DBMS yang didistribusikan secra gratis dibawah lisensi dari general public license (GPL), dimana setiap orang bebas untuk menggunakanya tetapi tidak boleh untuk dijadikan program induk turunan bersifat close source (komersial). Beberapa keunggulan dari MySQL.

1. Portability: dapat berjalan stabil pada berbagai system operasi, diantaranya 
windows, linux, FreeBSD, Mac OS Xserver, solaris, dan asigma.

2. Open source: didistribusikan secara gratis dibawah lisensi dari general public license dimana setiap orang bebas untuk menggunakanya tetapi tidak boleh menggunakan MySQL untuk dijadikan induk turunan yang bersifat close source (komersial).

3. Multi user : dapat digunakan oleh beberapa user dalam waktu yang bersamaan.

4. Performance tuning : mempunyai kecepatan yang tinggi dalam menangani quer.

5. Column types : memiliki tipe data yang sangat komplik.

6. Command dan function: memiliki operator dan fungsi penuh yang mendukung select dan where dalam query.

7. Security: memiliki beberapa lapisan sekuritas seperti tingkat subnet mask, hostname, privilege user dengan system perijinan yang mendetailserta password yang ter-enkripsi.

8. Scalability dan limits : mampu menangani basis data dalam jumlah besar.

9. Localization: dapat mendeteksi pesan kesalahan (error code) pada klien dengan menggunakan lebih dari 20 bahasa.

10. Connectivity: dapat melakukan koneksi dengan klien menggunakan protocol TCP/IP, Unix Socket, Named pipes.

11. Interface memiliki antarmuka terhadap berbagai aplikasi dan bahasa pemprograman dengan menggunakan fungsi API.

12. Clients dan tools: dilengkapi dengan berbagai tool yang dapat digunakan untuk administrasi basis data sekaligus dokumen petunjuk online.

13. Struktur table : memiliki struktur table yang lebih fleksibeldalam menangani alter table dibandingkan dengan postgre SQL dan oracle[8]

\section{LITERATURE REVIEW}

Banyak penelitian yang sebelumnya yang sebelumnya dilakukan mengenai system Pengajuan Cuti. Beberapa literature review sebagai berikut :

1. Penelitian yang dilakukan oleh Gandana Akhmad Syaripudin pada tahun 2012 yang berjudul "Pengembangan Aplikasi Web Untuk Pengajuan Cuti Pegawai Secara Online". Pada penelitian ini membahas mengenai aplikasi pengajuan cuti pegawai secara online yang dianggap penting karena memberikan manfaat dalam memberikan informasi dengan cepat, dan memberikan kemudahan bagi pegawai untuk dapat mengajukan cuti dan mengakses informasi cuti pegawai. Metodologi yang dipakai dalam pengembangan aplikasi ini adalah dengan menggunakan metode Unified Software Development Process. Aplikasi web untuk pengajuan cuti pegawai secara online yang dihasilkan dapat memberikan solusi bagi permasalahan yang ada. Maka dengan adanya aplikasi ini instansi terkait dapat memanfaatkannya untuk meningkatkan kinerja dan efisiensi waktu dalam kegiatan di bagian kepegawaian yaitu pengajuan cuti pegawai secara online.[9]

2. Penelitian ini dilakukan oleh Fransiskus Adikara pada tahun 2016 dengan judul "Pengembangan Fungsi pengajuan cuti karyawan pada system absensi mobile". Penelitian ini dilakukan dengan menggunakan metode pengembangan sistem Berbasis Gps MacAdrress. Keunggulan pada program ini karyawan dapat mengajukan cuti secara mandiri melalui perangkat mobile yang menggunakan minimal system operasi Android 4x untuk kombinasikan dengan berbasis GPS. Pengembangan fasilitas login system yang kredibel contohnya dengan menambahkan pemindai data biometric dari penggunanya.[10]

3. Penelitian yang dilakukan oleh Arif Setiyanto pada tahun 2013 dengan judul "Pembuatan Sistem Informasi Cuti pada Kantor Pelayanan Perbendaharaan Negara dengan 
Menggunakan PHP dan MySQL". Penelitian ini membahas mengenai Sistem informasi cuti yang dapat mempermudah dalam melakukan administrasi/pengurusan cuti dalam lingkup KPPN. Proses pengecekan hak cuti, pengajuan, serta pengambilan keputusan cuti terangkai secara sistematis. Beban kerja admin kepegawaian dalam mengurus administrasi cuti dapat dikurangi pada hal-hal tertentu, seperti pengecekan dan pengkartuan cuti. Setiap pegawai dapat memantau hak cuti serta pengambilan cuti pribadi dan rekan kerja. Dengan adanya transparansi tersebut, perencanaan dan manajemen cuti dapat dilakukan secara lebih baik oleh pegawai KPPN.[11]

4. Penelitian yang dilakukan oleh Oleh Soleh pada tahun 2013 dengan judul "Penerapan SMS Gateway Pada E Journal Sebagai Media Notification". Penelitian ini membahas mengenai sms gateway pada e-journal, akan memudahkan authors, dengan admin dan reviewernya dalam proses penerbitan jurnal, dan tidak harus online setiap saat hanya untuk melihat email notifikasi dari e-journal.[12]

Dari 5 (lima) literature review yang ada, telah banyak penelitian yang membahas mengenai sistem Pengajuan Cuti. Namun dapat disimpulkan bahwa belum ada peneliti yang secara khusus membahas mengenai system informasi cuti berbasis sms gateway. Oleh karena itu, untuk menindak lanjuti peneliti sebelumnya seperti yang dikemukakan diatas, maka dilakukan penelitian tentang Pengajuan cuti di perusahaan berbasis sms gateway.

\section{Metode Penelitian}

Metode penelitian ini adalah dengan menggunakan menggunakan metodologi waterfall yang dibatasi dan hanya dilakukan hingga tahap implementasi atau coding.

Di dalam international Journal of Scientific \& Engineering Research (2013:47), Waterfall Model adalah Pendekatan tradisional untuk pengembangan perangkat lunak dapat digambarkan melalui air terjun Model yang waktu-diuji dan mudah dimengerti. Model air terjun adalah model statis dan mendekati pengembangan sistem secara linear dan berurutan, menyelesaikan satu kegiatan sebelum yang lain.[14]

Untuk memperoleh data yang diperlukan metode pengumpulan data yang digunakan adalah sebagai berikut :

1. Metode Observasi

Melakukan tinjauan langsung ke tempat instansi yang ingin diteiti serta mengumpulkan data informasi mengenai pengajuan cuti pada perusahaan.

2. Metode Wawancara

Melakukan tanya jawab dengan yang bersangkutan dan yang berwenang untuk memperoleh data informasi yang diperlukan dan mengetahui alur kerja pada sistem tersebut.

3. Metode Studi Pustaka

Mencari data-data yang berkaitan dengan masalah-masalah yang dibahas dan diperoleh dari buku-buku dan media internet.

Ada Pun Perangkat lunak yang digunakan untuk membuat program sms geteway ini adalah:

1. Sistem operasi Windows 8

2. Bahasa Pemrograman PHP

3. Aplikasi Gammu

4. Aplikasi Apace Web Server (XAMPP)

5. Database Mysql 


\section{Macromedia Dreamweaver C6}

Perangkat keras adalah bagian fisik dari sistem komputer, untuk menjalankan sistem ini diperlukan sebuah personal komputer yang spesifikasinya minimum sebagai berikut:

1. Microsoft Windows 8

2. Komputer/Laptop

3. Hardisk 500GB

4. Memory 4GB

5. Modem Wavecom M1306B

Adapun rancangan sistem baru yang akan peneliti Rancang bangun menggunakan bahasa pemrograman macromedia dreamweaver Cs 6, Gammu, MySQL dan PHP. Karena dengan sistem layanan sms ini akan mempermudah dalam mendapatkan informasi Pengajuan Cuti secara cepat dan auto replay.

\section{PEMBAHASAN}

\section{Alternatif Pemecahan Masalah}

Untuk mengatasi permasalahan tersebut di atas, maka di rancanglah sistem informasi sebagai fasilitas permohonan cuti karyawan dengan sms Gateway dan masukan atau input yang diperlukan untuk membuat aplikasi cuti karyawan yaitu berupa form dan keluaran atau output yang akan dihasilkan yaitu berupa laporan data karyawan dan laporan berupa sms gateway.

Program tersebut nantinya akan menampilkan menu form update data karyawan, login, pengambilan cuti, data cuti, histori cuti, update data cuti, jenis cuti, marital, pendidikan, divisi, dan beberapa form untuk mencetak laporan dan bagaimana proses pengajuan cuti mulai dari karyawan mengisi formulir cuti kemudian di proses oleh bagian SDM dengan melihat catatan cuti karyawan tersebut kemudian diajukan kepada direktur untuk meminta persetujuan..

Volume data yang akan ditangani oleh aplikasi cuti karyawan yaitu banyaknya jumlah karyawan yang akan ditangani oleh aplikasi cuti ini.

Jumlah pemakai dan kategori pemakai yaitu kepala bagian SDM Kontrol terhadap aplikasi cuti karyawan yaitu aplikasi cuti ini harus tetap di kontrol agar tetap menghasilkan output sesuai dengan yang diinginkan dan menghindari penyalahgunaan dengan cara membuat password saat membuka aplikasi ini.

\section{Rancangan Sistem yang diusulkan}

Untuk menganalisa sistem yang dibuat dan yang ingin diusulkan pada penelitian ini digunakan program Visual Paradigm 6.4 Enterprise Edition untuk menggambarkan Usecase Diagram, Activity Diagram, dan Sequence Diagram.

Use Case Diagram yang diusulkan 


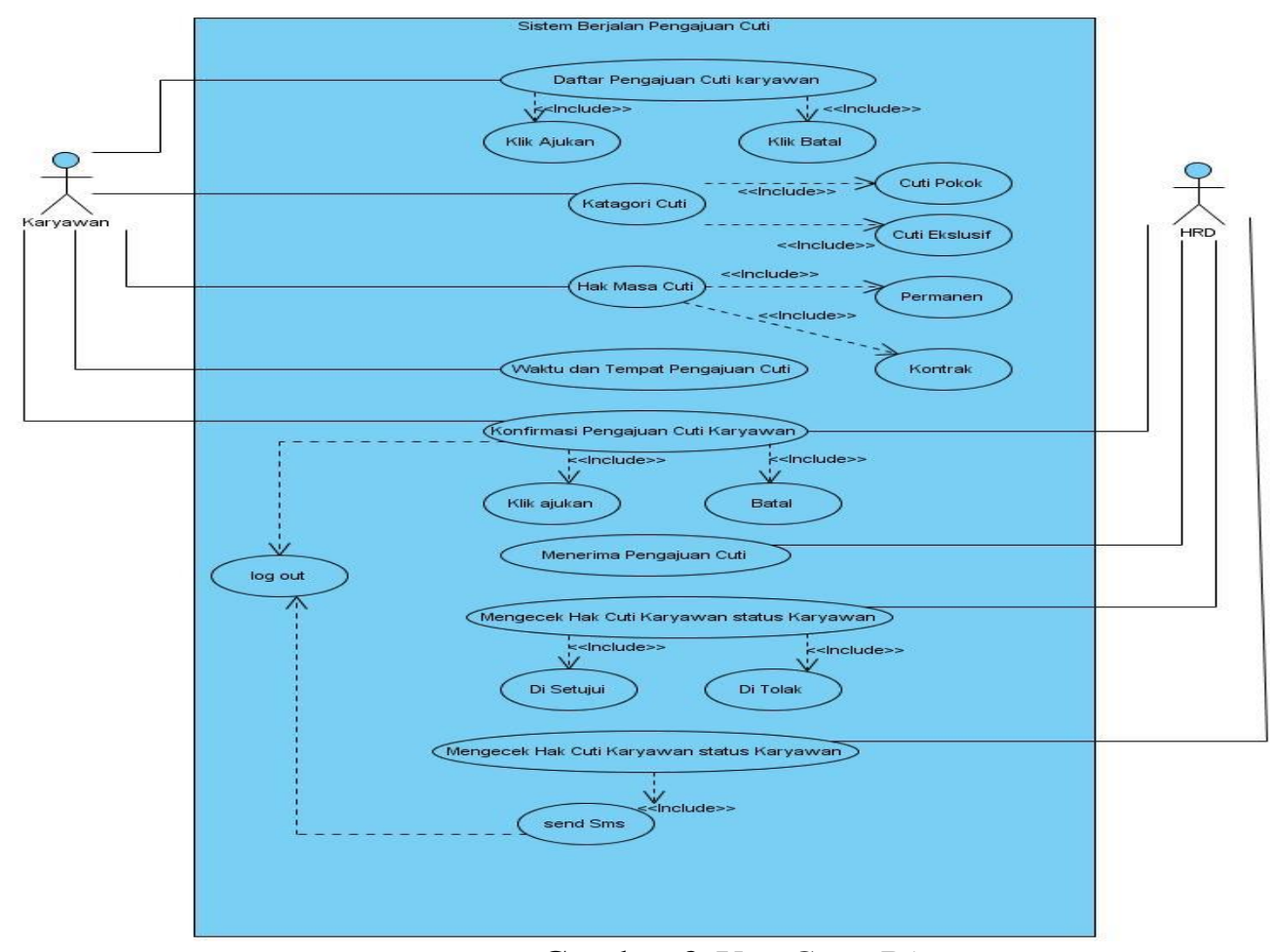

Gambar 2 Use Case Diagram

Berdasarkan gambar 2 Use Case Diagram pada sistem pengajuan cuti karyawan terdapat:

1. 1 (satu) sistem pengajuan cuti,diantaranya Karyawan

2. 1 (satu) actor yang melakukan kegiatan, diantaranya Hrd

3. 10 (sepuluh) use case yang dilakukan oleh para actor

4. 11 (Sebelas) Include yang dapat diartikan sebagai kegiatan yang harus dilakukan setelah melakukan Parent Use Case.

\section{Activity Diagram yang diusulkan}

Activity Diagram Karyawan

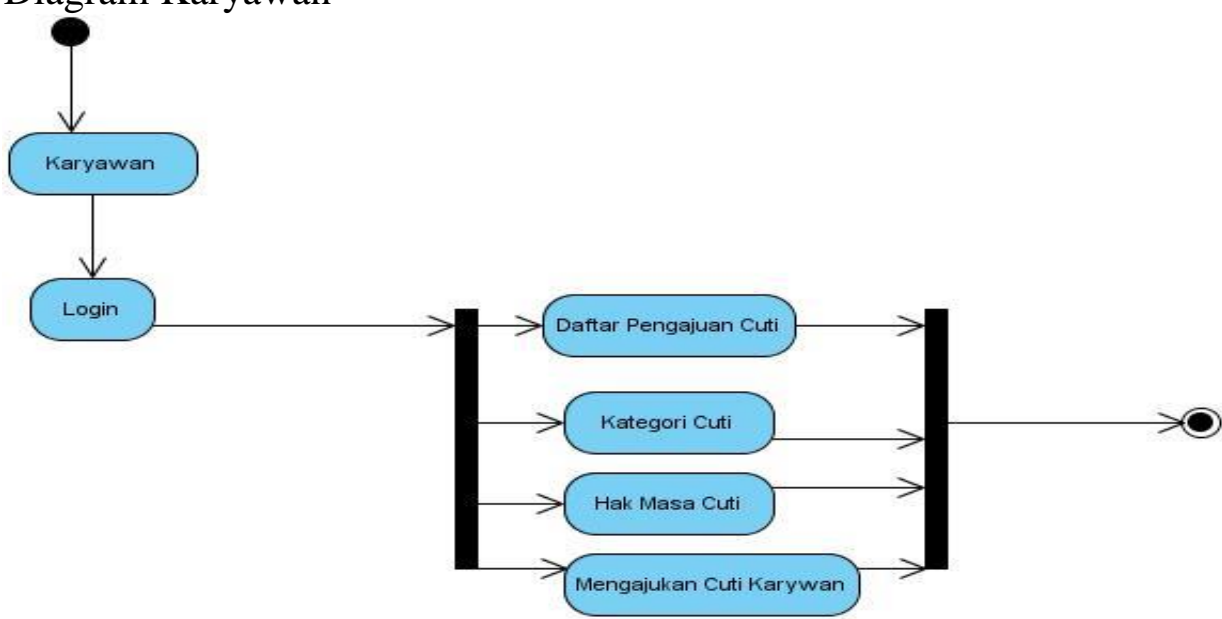

Gambar 3 activity diagram hrd pada sistem

Berdasarkan pada gambar 3 activity Diagram pada karyawan terdapat :

a. 1 (satu) Intial Node, objek yang diawal

b. 6 (enam) action, state dari sistem mencerminkan eksekusi dari suatu aksi

c. 1 (satu) Final State, objek yang diakhiri 


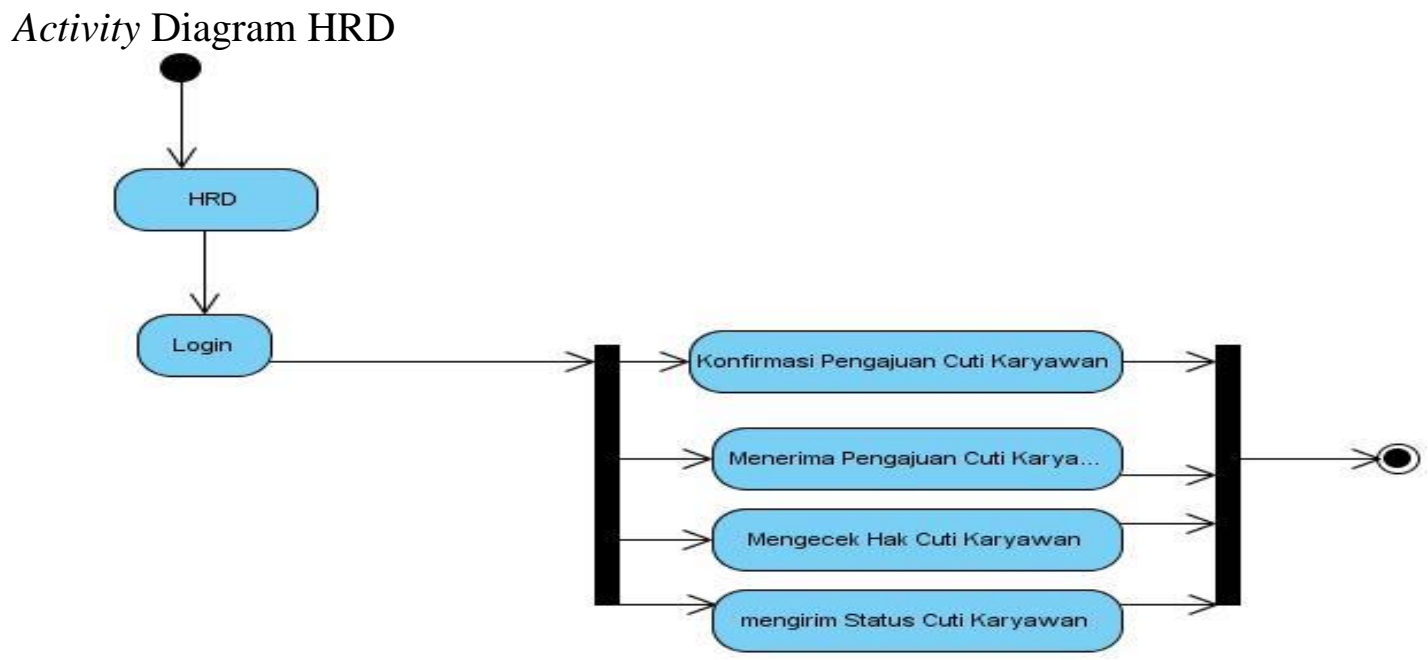

Gambar 4 activity diagram HRD pada sistem pengajuan cuti

Berdasarkan pada gambar 4 activity Diagram pada karyawan terdapat :

a. 1 (satu) Intial Node, objek yang diawai

b. 6 (enam) action, state dari sistem mencerminkan eksekusi dari suatu aksi

c. 1 (satu) Final State, objek yang diakhiri

\section{Implementasi}

Hasil dari implementasi sistem informasi interface dapat terlihat seperti pada gambar-gambar berikut :

1. Form Menu Utama

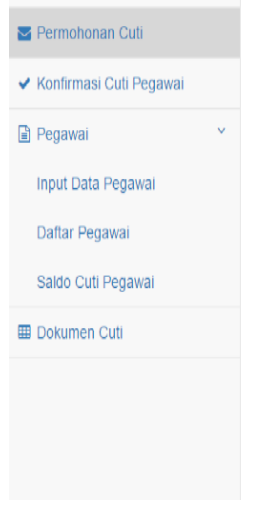

\section{Permohonan Cuti}

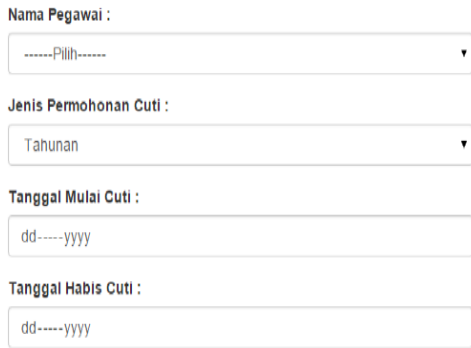

\section{Gambar 6 Form Menu Utama}

Gambar 6 Form Menu Utama menampilkan menu Utama pada bagian pedaftaran permohonan cuti, terdapat berkas nama pegawai , tanggal mulai cuti, tanggal abis cuti, dan lama cuti. Pada menu berkas terdapat kelola pegawai, kelola data pegawai, dokumen cuti, dan keluar, pada menu data karyawan terdapat pendaftaran karyawan cuti, pencarian data karyawan, pada menu laporan terdapat laporan data karyawan, pada menu windows untuk mengganti desain tampilannya. Ada pun beberapa button yaitu pendaftaran karyawan, data karyawan, laporan, konfirmasi karyawan, dan keluar. Aplikasi ini di desain disesuaikan dengan keinginan pihak instansi dan sesimple mungkin penampilannya agar mempermudah dalam menggunakan aplikasi ini dan dapat secara cepat mengerti dalam penggunakan aplikasi ini. 
2. Form Input Data Permintaan cuti

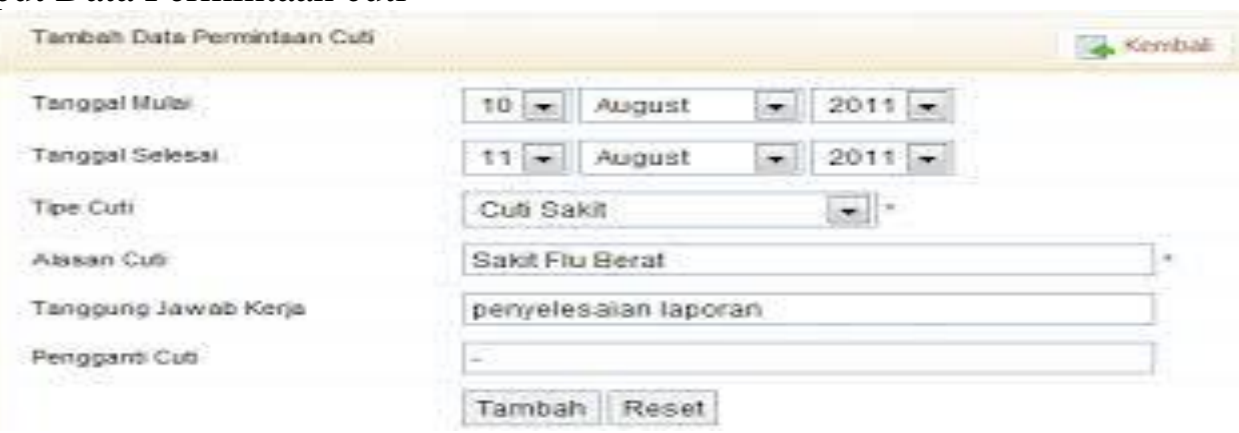

Gambar 7 Form Data Permintaan cuti

Gambar 7 Form Data Permintaan cuti menampilkan pendaftaran cuti, form ini berfungsi untuk pendaftaran permintaan cuti, di form ini terdapat tanggal mulai, tanggal selesai, tipe cuti, terdapatnya alasan cuti, jam secara otomatis akan memudahkan pengguna agar tidak mengetik tanggal dan jam karena tanggal dan jam akan otomatis muncul sesuai tanggal dan jam hari cuti karyawan yang akan mendaftar. Form input data permintaan cuti terdapat button save, delete, search kembali dan registrasi karyawan yang tentunya akan mempermudah pengguna dalam hal menyimpan data permintaan cuti karyawan, form ini disesuaikan dengan pendaftaran tempat instansi tersebut karena untuk mempermudah pengguna dalam pemakaian aplikasi ini.

3. Form Registrasi Permintaan cuti karyawan

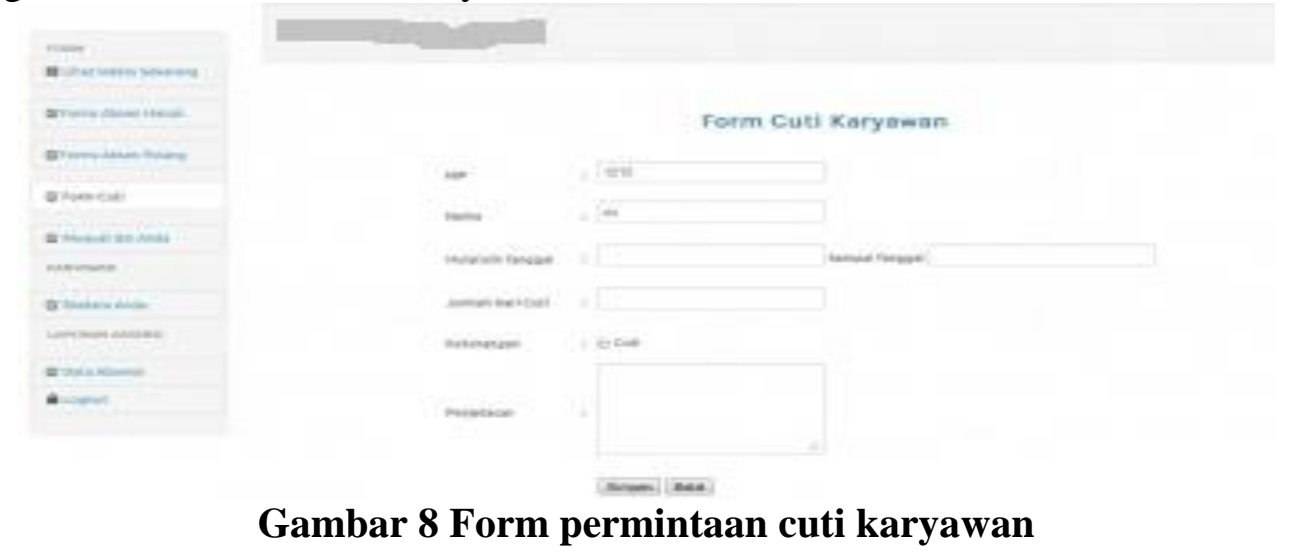

Gambar 8 Form Registrasi Permintaan cuti karyawan menampilkan from cuti karyawan. Form ini terdapat nomor induk pegawai, nama karyawan, tanggal Cuti karyawan, save, delete, permintaan cuti karyawan menampilkan data-data karyawan dan laporan cuti karyawan, yang sesuai dengan layanan yang akan mempermudah pengguna dalam mencari data karyawan untuk cuti yang harus di isi sesuai layanan yang akan di gunakan perusahaan. Data karyawan terdapat data yang mendaftar dengan menggunakan from cuti karena karyawan mendaftar dengan memasukan data ke from cuti karyawan, menggunakan aplikasi khusunya form registrasi pun di permudah dan disesuaikan dengan keinginan pihak instansi agar pengguna dapat mudah mengerti dalam hal pemakaian aplikasi khususnya form registrasi. 
4. Form laporan pengajuan cuti karyawan

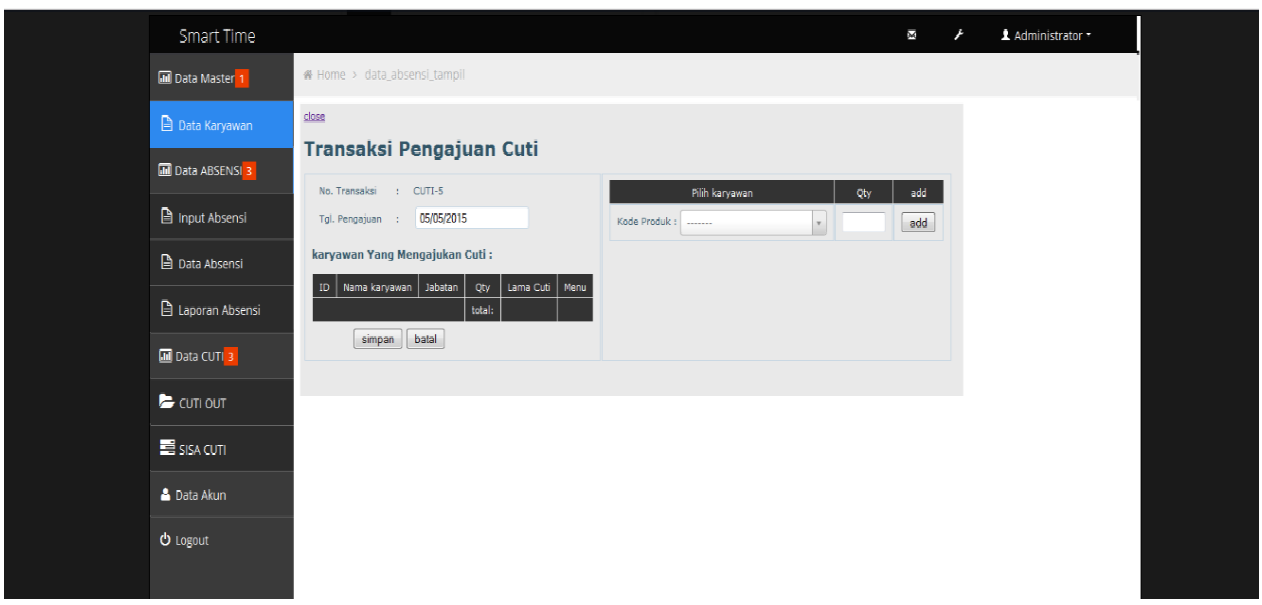

Gambar 9 Form laporan cuti karyawan

Gambar 9 Form Input laporan cuti karyawan menampilkan form laporan cuti karyawan dari sms gateway. Form ini digunakan untuk menginput data pengajuan cuti yang mengajukan. Form ini khusus untuk data-data pengajuan karyawan yang menggunanya pun sangat mudah, pengguna hanya mengetik di text search guna ingin mencari data karyawan yang sudah mendaftar dan akan muncul sesuai nama karyawan yang kita cari. Data pengajuan cuti guna melengkapi sisa cuti karyawan. Form ini terdapat beberapa button seperti save guna menyimpan data pengajuan cuti karyawan baru, delete guna mendelete karyawan yang sudah habis masa cutinya, kembali untuk kembali ke form utama, button pilih scan untuk menscan form yang diisi oleh Personalia untuk karyawan yang melakukan cuti karyawan agar mempermudah pemakai agar tidak mengetik kembali, scan pemeriksa untuk menscan khususnya dalam pemeriksaan dari personalia agar mempermudah pemakai agar tidak mengetik ulang. Desain penampilannya pun disesuaikan keinginan instansi agar mudah dalam pemakainya.

\section{Form Menu Utama SMS Gateway}

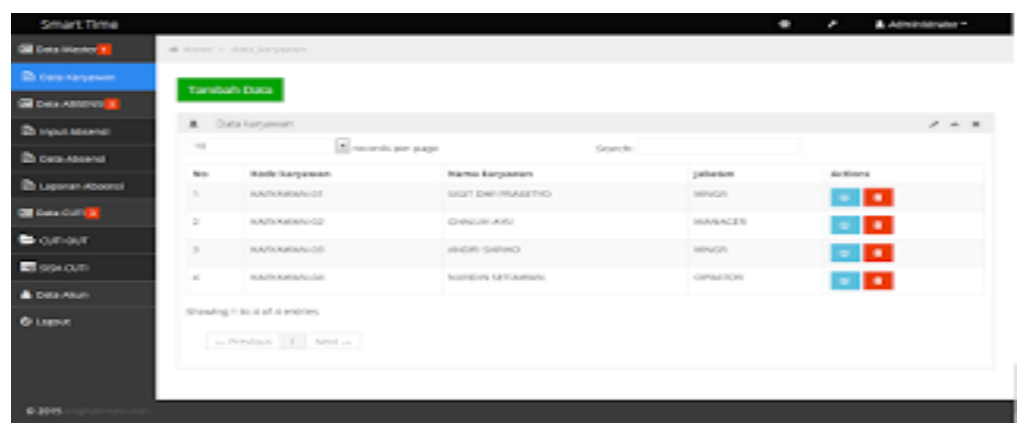

Gambar 10 Gambar Form Menu Utama sms gateway

Gambar 10 Form Menu Utama sms gateway menampilkan menu utama untuk bagian Data Karyawan. Form ini menampilkan menu-menu seperti menu data master yang terdapat data karyawan, data absen, laporan absen, data cuti, cuti out, sisa cuti, untuk mengubah template agar pengguna tidak bosan untuk menngunakannya, dan yang terakhir menu keluar berguna untuk keluar dari aplikasi sms gateway, menu-menu tersebut menampilkan yang sesuai dengan nama menu-menu tersebut. Desain aplikasi cuti karyawan pun disesuaikan dengan keinginan pihak instansi karena agar dapat mempermudah dan cepat mengerti dalam hal 
menggunakan aplikasi.

6. Form laporan cuti karyawan

\begin{tabular}{|c|c|}
\hline FORM CUTI & \\
\hline curr-4 & \\
\hline
\end{tabular}

\begin{tabular}{|c|c|c|c|c|c|c|}
\hline No & NIK & NAMA KARYAWAN & JABATAN & LAMA CUTI & UNIT/ DAY & KETERANGAN \\
\hline 1 & KARYAWAN-01 & SIGIT DWI PRASETYO & MNGR & 1 & hari & \\
\hline
\end{tabular}

\begin{tabular}{|l|l|l|l|}
\hline \multicolumn{1}{|c|}{ ISSUED BY } & \multicolumn{1}{|c|}{ APROVED BY } & \multicolumn{1}{c|}{ DELIVERED BY } & \\
& & & \\
& & & \\
\hline NAMECEIVED BY & & & \\
\hline DATE : & NAME : & NAME : & NAME : \\
\hline
\end{tabular}

FRM/GP/MM-05/002/A

\section{Gambar 11 Form laporan cuti karyawan}

Gambar 11 Form hasil laporan cuti karyawan menampilkan data-data nama karyawan yang sudah di input dan untuk pencarian data karyawan. Di form ini terdapat Option Button seperti no , nik, nama karyawan, jabatan, lama cuti, unit hari, keterangan. Option button digunakan untuk mempermudah mencari data karyawan, data karyawan baru ataupun data karyawan lama, seusai option button yang dipilih pengguna. Dan terdapat pula combobox khususnya untuk tanggal dan button cari data digunakan agar mempermudah mencari data karyawan yang terdaftar sesuai tanggal cuti mendafatar dan sampai tanggal cuti berakhir. Form ini di desain simple tapi menarik agar pengguna dapat mudah mengerti dalam memakai aplikasi ini.

7. Form Persetujuan cuti ponsel

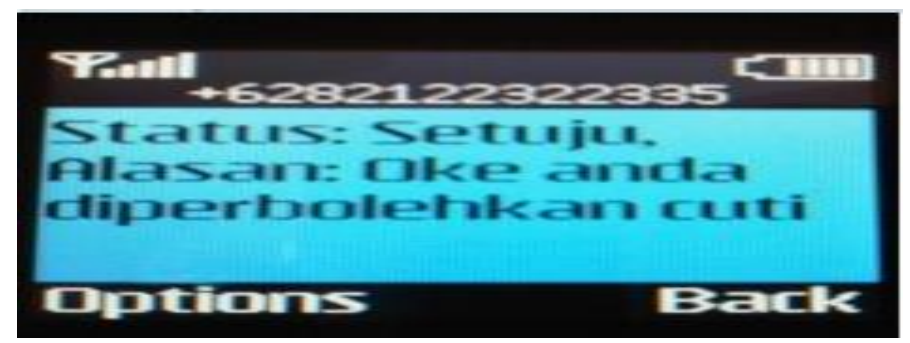

Gambar 12 Tampilan persetujuan cuti ponsel

Pada Gambar 12 merupakan tampilan pada ponsel karyawan setelah HRD mengkonfirmasi cuti melalui aplikasi gammu sebagai sms gateway, hasil konfirmasi beserta alasannya di kirim langsung ke ponsel karyawan Tersebut.

\section{Kesimpulan}

Berdasarkan implementasi dan evaluasi yang telah dilakukan, dapat disimpulkan bahwa

1. Aplikasi SMS Gateway yang dibangun dengan menggunakan software Gammu dengan menggunakan bahasa pemrograman PHP sebagai awal peng-inputan data pengajuan yang disimpan pada database MySQL, kemudian dihubungkan dengan konsep client-server yang sesuai dalam Osi layer, serta output hasil memanfaatkan fasilitas sms gateway memudahkan proses pengajuan, pengecekan dan pengambilan keputusan hak cuti pegawai dapat dilakukan secara sistematis, selain itu,proses pengajuan cuti bisa menjadi lebih transparan.

2. Dengan adanya aplikasi SMS gateway ini, dapat digunakan untuk informasi Cuti karyawan dengan mengetikan format sms yang telah disediakan sehingga dapat 


\section{Saran}

membantu HRD dalam mengirim informasi tentang Cuti terhadap karyawan tersebut.

Sms gateway dalam informasi Cuti karyawan pada Program PT Bermuda Communication ini walaupun belum begitu sempurna, diharapkan dapat dikembangkan lebih lanjut, sehingga tampilannya dapat lebih menarik, kreatif, dan variatif Setiap pengaturan gammu diberbagai sistem operasi sangatlah berbeda, memerlukan ketelitian dalam pengkoneksian dan database yang terhubung langsung sehingga tidak terjadi error dalam instalasi gammu Perlu meningkatkan pengetahuan agar program dapat dihubungkan ke website utama PT Bermuda Communication.

\section{DAFTAR PUSTAKA}

[1] Stair and Reynolds. 2010. "Definisi Analisa Sistem Adalah Fase Pengembangan Sistem". Jakarta

[2] Aisyah, Siti, Nawang Kalbuana. 2011. Perancangan Aplikasi Akademik Teknologi Mobile Menggunakan J2ME. CCIT Journal Vol. 4 No.2-Januari 2011, STMIK Raharja.

[3] Shu Chiang Lin, Reny Nadlifatin. 2014. "Toward Paperless Public Announcement on Environmental Impact Assessment (EIA) through SMS Gateway in Indonesia": Department of Industrial Management, National Taiwan University of Science and Technology.

[4] Fahrudin, Tara. 2012. Notifikasi Jatuh Tempo Tunggakan Kuliah Mahasiswa Berbasis SMS Gateway dan Aplikasi Web (Studi Kasus Politeknik Telkom Bandung). Bandung: Politeknik Telkom.

[5] Ibrahim, Ali. 2011. "Pengembangan Sistem Informasi Monitoring Tugas Akhir Berbasis Short Message Service (SMS) Gateway di Fasilkom Unsri”. Yogyakarta: Jurnal Sistem Informasi Indonesia Vol. 1 No. 2:81-92.

[6] Menteri Ketenagakerjaan Republik Indonesia No.13 tahun 2003 pasal 79.

[7] Arief, M.Rudianto. 2011. Pemrograman Web Dinamis Menggunakan Php dan Mysql. Yogyakarta: Andi.

[8] Sutaji, Deni. 2012. "Sistem Informasi Mini Market dengan PHP dan JQuery". Yogyakarta:Lokomedia.

[9] Akhmad S, Gandana, Cahyana, Rinda. 2015. Pengembangan Aplikasi Web Untuk Pengajuan Cuti Pegawai Secara Online. Jurnal Sistem Informasi Vol. 13 No. 1. Sekolah Tinggi Teknologi, Garut.

[10] Adikara, Fransiskus. 2016. Pengembangan Fungsi pengajuan cuti karyawan pada system absensi mobile. Jurnal SISFO. Universitas Esa Unggul. Jakarta.

[11] Setiyanto, Arif. Samopa, Febriliyan dan Alwi. 2013. Pembuatan Sistem Informasi Cuti pada Kantor Pelayanan Perbendaharaan Negara dengan Menggunakan PHP dan MySQL. JURNAL TEKNIK POMITS Vol. 2, No. 2, (2013). Institut Teknologi Sepuluh Nopember (ITS). Surabaya.

[12] Soleh, Oleh, dkk, 2013. Penerapan SMS Gateway Pada E Journal Sebagai Media Notification. Seminar Nasional Teknologi Informasi dan Multimedia 2013. STMIK AMIKOM Yogyakarta, 19 Januari 2013.

[13] Noor, Tajudin, dkk. 2015. Aplikasi Sistem Berbasis Sms Gateway Menggunakan Gammu, Php Dan Mysql (Studi Kasus : Kantor Dinas Perhubungan Komunikasi Dan Informatika Banjarmasin. Jurnal POSITIF, Tahun I, No.1, November 2015. Politeknik Negeri Banjarmasin.

[14] AdetokunboA.A.2013,"Software Engineering Methodologies: A Review of the Waterfall Model and Object- Oriented Approach". ISSN 2229-5518. 